\title{
Health-related Quality of Life of Cancer Caregivers in Klang Valley, Malaysia
}

\author{
Nik Nairan Abdullah¹, Idayu Badilla Idris ${ }^{2}$, Hamidah Yamat ${ }^{3}$, Nik Muhd Aslan Abdullah \\ 1 Department Public Health Medicine, Faculty of Medicine, Universiti Teknologi MARA,Sungai Buloh,Selangor,Malaysia \\ 2 Department of Community Health,Faculty of Medicine,Universiti Kebangsaan Malaysia,Kuala Lumpur,Malaysia \\ ${ }^{3}$ Faculty of Education, Universiti Kebangsaan Malaysia,Bangi,Selangor,Malaysia \\ ${ }^{4}$ Oncology Department,Sunway Medical Centre,Petaling Jaya,Selangor,Malaysia.
}

niknairan@gmail.com, idayubadilla.idris@gmail.com, hamidah_yamat@ukm.edu.my,nmaslan@gmail.com

Tel : 03-61267214

\begin{abstract}
Cancer caregiving has an impact on the quality of life (QOL) of the caregivers. This cross-sectional study determined the health-related QOL (HRQOL) of gastrointestinal cancer caregivers and associated factors across gender. A total of 323 respondents from major hospitals in Klang Valley completed HRQOL questionnaire from October 2017 to April 2018. Males had a better quality of life compared to females, mean HRQOL score 85.52 (SD=21.16) vs 77.66 ( $\mathrm{SD}=21.36$ ). The significant factors were: relationship between the caregiver and the patient; education level; employment status, marital status, household income and presence of disease. The gender role is vital for targeted intervention.
\end{abstract}

Keywords: health-related quality of life; gastrointestinal cancer; caregivers; gender

eISSN: 2398-4287C 2020. The Authors. Published for AMER ABRA cE-Bs by e-International Publishing House, Ltd., UK. This is an open access article under the CC BYNC-ND license (http://creativecommons.org/licenses/by-nc-nd/4.0/). Peer-review under responsibility of AMER (Association of Malaysian Environment-Behaviour Researchers), ABRA (Association of Behavioural Researchers on Asians) and cE-Bs (Centre for Environment-Behaviour Studies), Faculty of Architecture, Planning \& Surveying, Universiti Teknologi MARA, Malaysia.

DOI: https://doi.org/10.21834/ebpj.v5i15.2453

\subsection{Introduction}

Gastrointestinal cancer is a significant public health concern. Cancer is a form of chronic disease, and life expectancy of a patient varies according to the disease characteristics and the treatment received. According to the National Registry of Cancer Report, a total number of 103,507 new cancer cases were diagnosed in Malaysia from 2007 to 2011. The registry estimated that 45.2\% of cases were reported in males while $54.8 \%$ of patients were in females. Colorectal cancer is the most common cancer among men and the second common among women (Azizah et al., 2015). Colorectal cancer is regarded as one of the prevalent cancers in the lower part of the gastrointestinal system.

Cancer is one of the chronic illnesses that evolve throughout the life span of the patient. The illness trajectory affects not only the quality of life of the patients but also the health-related quality of life of caregivers. Cancer causes numerous health issues and produces a negative impact on the quality of life (QOL) of their caregivers. Due to the increasing trend of this type of gastrointestinal cancer, the number of family members caring for these cancer patients increased as well. With the advanced treatment that required less inpatient care and more extended survival periods of cancer patients, caregivers are required to provide informal care outside of the hospital settings.

eISSN: 2398-4287C 2020. The Authors. Published for AMER ABRA cE-Bs by e-International Publishing House, Ltd., UK. This is an open access article under the CC BYNC-ND license (http://creativecommons.org/licenses/by-nc-nd/4.0/). Peer-review under responsibility of AMER (Association of Malaysian Environment-Behaviour Researchers), ABRA (Association of Behavioural Researchers on Asians) and cE-Bs (Centre for Environment-Behaviour Studies), Faculty of Architecture, Planning \& Surveying, Universiti Teknologi MARA, Malaysia.

DOI: https://doi.org/10.21834/ebpj.v5i15.2453 
Cancer caregiver is a person who most often helps the person with cancer and is not paid to do so. Caregivers have many roles, and these roles change as the patient's needs change during and after cancer treatment such as dispensing medications to the patient, managing the side-effects of treatment and assisting patients in deciding on treatments. The informal care provided by the caregivers during the progression of the illness resulted in increased responsibilities and commitments, which in the long term affect the caregivers' quality of life (Franchini et al., 2019). Besides, caregivers may lose control over their lives, and caregiving may have an adverse effect on their social, work, family/marital life, and causes their quality of life to deteriorate (Turkoglu \& Kilic, 2012). Their role is tremendous and may create a burden to them, especially when there are not trained and have lack of experience caring for a patient with a chronic and debilitating disease.

Throughout the process of caregiving, caregivers face health problems, and the consequences may have an impact on the patients' quality of life. Family caregivers have to cope with various aspects of their lives, such as physical, social, and economic problems during the caregiving process. The decrease in the caregiver's quality of life influences the quality of care and quality of life of the patient (Turkoglu \& Kilic,2012). Therefore, healthcare providers need to be aware of the levels of the QOL of the caregivers so that the caregiving process is not compromised. By knowing the health state of the caregivers, health personnel can plan for intervention in the future.

Because of the growing importance of cancer caregivers in the patient's care, there is a need to conduct a local study. The rationale for conducting this study was the lack of published literature on the QOL of gastrointestinal cancer caregivers across gender in the local population. The study's objectives were to determine the health-related QOL (HRQOL) of gastrointestinal cancer caregivers and associated factors across gender.

\subsection{Literature Review}

\subsection{Health-related Quality of Life}

The Quality of Life is a multidimensional construct that is dynamic and changes with time. The Quality of Life constructs is a subjective measure that is based on individual evaluations and perceptions of life. This measurement gives insights into the feeling of what is important to the well-being and being satisfied with things in general. The QOL encompassed aspects related to the cognitive experience (judgement, beliefs, evaluation), affective aspects of experience (feeling) and behaviour dimension (Mohit, 2018).

Socio-demographic of the individual, religion is few of the determinants of QOL. Azizan \& Mahmud (2018) found that socio-economic attributes such as income, financial and employment status are the most common determinants of subjective well-being being studied. In medical studies, health-related quality of life or known as HRQOL is a more frequently used terminology because the factors elucidated contributed to the health aspects besides the study population's well-being. HRQOL has been utilised in cancer research studies and is useful for several reasons. The use of HRQOL in the cancer population was beneficial to investigate the effects of cancer and its treatment. Among the caregivers, HRQOL instrument can be useful to healthcare professionals because it gives an indicator of the caregiver's health status and identifies caregivers at risk. Such a tool is also beneficial to the caregivers not only to the healthcare personnel. It often allows caregivers to become aware of their needs. Franchini et al. (2019) documented that the QOL of caregivers can be affected by the patient- or treatment-related factors, socio-economic status, characteristics of caregivers themselves (e.g., gender, age), and caregiving aspects (e.g., time spent in taking care of the patient).

Multiple instruments measure HRQOL in the caregiver population. These instruments are divided into generic and specific purposes. For the generic purpose, the commonly used tools are Medical Outcomes Study 12-item Short Form (MOS SF-12) version two, Medical Outcome Study 36-item (SF-36) and World Health Organization Quality of Life (WHOQOL). On the other hand, specific HRQOL instruments are Caregiver Quality of Life-Cancer (CQOLC), the Caregiver Quality of Life Index and the Quality of Life Tool. The CQOLC was developed by Weitzner et al. (1999) to assess the QOL of family caregivers of patients with cancer. It is commonly used and has been validated in numerous languages worldwide.

In Malaysia, CQOLC tool has been used in the local population. Lua et al. (2013) used a validated Caregiver Quality of Life questionnaire in Bahasa Malaysia among HIVIAIDS caregivers and epilepsy caregivers. It is used to assess important aspects of QOL, including physical, emotional, family, and social functioning. The instrument was found to be valid and reliable in the previous study population. However, to our knowledge, it has not been used in the caregivers of the cancer population.

\subsection{Caregivers' Quality of Life}

Studies have reported that socio-demographic characteristics of patients and caregivers influenced the QOL of the caregivers. In addition, the clinical characteristics of the disease can also predict and have statistically significant effects on the QOL of the caregivers (Almutairi et al.,2017; Franchini et al.,2019)

In the cancer caregiving framework, the health or well-being of a caregiver (HRQOL) is the outcome of a stress process originating from multiple stressors. This framework adopted the stress process model. Based on this model, it was hypothesised that appraisal of caregiving has a strong relationship with QOL. A positive appraisal which is related to the caregivers' esteem is associated with a better QOL. This means a lower level of psychological distress and higher levels of mental and physical functioning and spiritual adjustment. On the other hand, a negative appraisal of caregiving (caregiving stress) would be associated with lower quality of life, a higher level of psychological distress and lower levels of mental and physical functioning and spiritual adjustment (Kim, Baker \& Spillers, 2007). Gender is one of the vital socio-demographic characteristics of the study population and is commonly studied. A previous study documented that gender has been recognised as the most predictive or risk factor of negative caregiving experience (Li, Mak \& Loke, 2012). Thus, the gender of the caregiver is associated with his/her HRQOL (Lim et al., 2016; Zhu et al., 2013) 


\subsection{Methodology}

A cross-sectional study was carried out from October 2017 until March 2018 at oncology departments in three tertiary centres located in Klang Valley. The gastrointestinal cancer patients at these locations identified their primary caregivers. The researchers explained the purpose of the study. The caregivers gave written consent to participate. Systematic random sampling was used to recruit the primary caregivers of gastrointestinal cancer patients. The inclusion criteria for the caregivers were respondents aged 18 and above, Malaysian, able to understand and read Bahasa Melayu, free from any diagnosed cancer. A total of 323 caregivers took part in the study. The data were collected via interview using a set of questionnaire. This study received ethical approval from the National Medical Research Registry.

\subsection{Instrument for Data Collection}

This study utilised a standard validated questionnaire in Bahasa Melayu. The questionnaire consisted of various parts which were sociodemographic factors and Caregiver Quality of Life-Cancer. The Caregiver Quality of Life (CQOLC) was used to measure the HRQOL of family caregivers to cancer patients. They are measured in terms of burden, disruptiveness, positive adaptation, and financial concerns. It contains 35 items which have 5 point response scale. The scale ranges from (1) not at all to (4) very much. Out of the 35 items, ten are on the burden, seven are on disruptiveness, seven are on positive adaptation, three are on financial concerns, and eight are on additional factors (disruption of sleep, satisfaction with sexual functioning, day-to-day focus, mental strain, being informed on the disease, protection of the patient, pain management, and family interest in caregiving). The maximum total score for CQOLC is 140, and higher scores show better HRQOL (Weitzner et al., 1999).

\subsection{Data Analysis}

Statistical Package for the Social Science (SPSS) version 20.0 was used for data analysis. Data entered were checked for missing data, and wrong entry before analysis was conducted. Descriptive analysis was performed to determine the socio-demographic of the caregivers. The mean scores of CQOLC were calculated for male and female caregivers' HRQOL. Independent t-test measured any significant difference between the mean scores of these two groups. In addition, Chi-square analysis was used to identify significant factors between male and female caregivers. A two-tailed analysis was used, and any factors with a p-value less than 0.05 was considered statistically significant.

\subsection{Findings}

The study population comprised of 323 caregivers. Out of the total, $103(31.9 \%)$ were males, and $68.1 \%$ were females. More than half of the study population were Malays (51.7\%), followed by Chinese $(35 \%)$ and others $(13.3 \%)$. Most of the caregivers were married (74.9\%). Estimated $43 \%$ of the caregivers attained secondary education level. A majority of them were working (60.4\%). About 150 caregivers (46.4\%) were spouse to the patients. It is estimated that $34.7 \%$ of the caregivers reported that they have one or more chronic diseases (Table 1).

From table 1, factors that were significantly different between males and females were: relationship between the caregiver and the patient, $X^{2}=16.25, p$-value $=0.001$; education level, $X^{2}=9.97, p$-value $=0.019$; employment status, $X^{2}=33.80, p$ - value $=<0.001$; marital status, $X^{2}=6.07, p$-value $=0.048$; household income, $t=2.32, p$-value $=0.021$ and presence of disease, $X^{2}=5.94, p$ - value $=0.015$. Other factors such as ethnicity, marital status and having children were not significant across the gender. Male caregivers had higher household income than females, RM4903.40 vs RM3895.59, mean difference $=1007.81$, p-value $=0.021$ (Table 2).

Table 2 showed the mean HRQOL scores (CQOLC) for males, $85.52 \pm 21.16$ were significantly higher than females, $77.66+21.36$, mean difference of $7.86 \pm 2.54, t=3.09, p$-value $=0.002$. The male caregivers had higher $Q O L$ scores compared to females, and the difference is significant. For the HRQOL domains, burden, positive adaptations, and others were significant between the genders. We tested the reliability of CQOLC, and the reliability of the questionnaire was good, Cronbach alpha of 0.90 .

Table 1. Health-related Quality of Life between male and female caregivers

\begin{tabular}{|c|c|c|c|c|c|}
\hline & $\begin{array}{l}\text { Male } \\
n=103\end{array}$ & $\begin{array}{l}\text { Female } \\
n=220\end{array}$ & $\mathrm{X}^{2}$ & $d f$ & $p$-value \\
\hline Ethnicity & & & 1.15 & 2 & 0.563 \\
\hline Malay & 53 & 114 & & & \\
\hline Chinese & 39 & 74 & & & \\
\hline Others & 11 & 32 & & & \\
\hline Marital status & & & 6.07 & 2 & $0.048^{*}$ \\
\hline Single & 27 & 41 & & & \\
\hline Married & 69 & 173 & & & \\
\hline Divorced & 7 & 6 & & & \\
\hline Education level & & & 9.97 & 3 & $0.019^{*}$ \\
\hline None & 2 & 11 & & & \\
\hline Primary & 7 & 22 & & & \\
\hline Secondary & 36 & 103 & & & \\
\hline Tertiary & 58 & 84 & & & \\
\hline Employment & & & 33.80 & 1 & $<0.001^{*}$ \\
\hline Work & 86 & 109 & & & \\
\hline Not working & 17 & 111 & & & \\
\hline Having children & & & 1.66 & 1 & 0.197 \\
\hline
\end{tabular}




\begin{tabular}{|c|c|c|c|c|c|}
\hline No & 35 & 60 & & & \\
\hline Yes & 67 & 160 & & & \\
\hline Relationship with patient & & & 16.25 & 3 & 0.001 \\
\hline Spouse & 33 & 117 & & & \\
\hline Child & 51 & 67 & & & \\
\hline Parent & 13 & 17 & & & \\
\hline Others & 6 & 19 & & & \\
\hline Presence of disease & & & 5.94 & 1 & 0.015 \\
\hline No & 77 & 134 & & & \\
\hline Yes & 26 & 86 & & & \\
\hline
\end{tabular}

Table 2. HRQOL and household income across gender

\begin{tabular}{|c|c|c|c|c|c|}
\hline & $\begin{array}{c}\text { Male }(n=103) \\
\text { Mean (SD) }\end{array}$ & $\begin{array}{c}\text { Female }(n=220) \\
\text { Mean(SD) }\end{array}$ & Mean difference(SE) & $t$ & $p$-value \\
\hline $\begin{array}{l}\text { HRQOL scores } \\
\text { HRQOL domains }\end{array}$ & $85.52(21.16)$ & $77.66(21.36)$ & $7.86(2.54)$ & 3.09 & $0.002^{*}$ \\
\hline Burden & $24.74(8.31)$ & $21.40(8.29)$ & $3.33(0.99)$ & 3.36 & $0.001^{*}$ \\
\hline Disruptiveness & 21.15(5.96) & $20.27(6.59)$ & $0.87(0.76)$ & 1.14 & 0.25 \\
\hline $\begin{array}{c}\text { Positive } \\
\text { adaptation }\end{array}$ & $18.89(5.46)$ & $20.84(5.44)$ & $-1.95(0.65)$ & -3.00 & $0.003^{*}$ \\
\hline Financial & $8.20(3.3)$ & $8.02(3.80)$ & $0.18(0.43)$ & 0.42 & 0.68 \\
\hline Others & $22.78(5.36)$ & $20.54(6.00)$ & $2.24(0.69)$ & 3.24 & $0.001^{*}$ \\
\hline $\begin{array}{c}\text { Household } \\
\text { income }\end{array}$ & $\begin{array}{c}4903.40 \\
(3848.54)\end{array}$ & $\begin{array}{c}3895.59 \\
(3530.26)\end{array}$ & 1007.81 & 2.32 & $0.021^{*}$ \\
\hline
\end{tabular}

\subsection{Discussion}

Our finding is similar to studies which found that gender was a significant predictor in caregivers' QOL (Almutairi et al., 2017; Franchini et al., 2019; Turkoglu \& Kilic, 2012). On the contrary, other studies found no significant association between gender and caregiver QOL (Doubova and Infante-Castaneda, 2016; Son et al., 2012).

Male caregivers had better QOL than females in our study. This finding is consistent with previous studies. Female caregivers showed a worse QOL compared with men (Franchini et al., 2019). In non-cancer population, QOL was statistically significantly higher in males than in females of psychology undergraduates (Chraifa \& Dumitrub, 2015). However, our finding is incongruent with Lim et al. (2016). The author reported that male caregivers had more impaired QOL than their female peers. According to the author, the need to balance work and family needs caused additional role strain to the male caregivers. In addition, there is increasing involvement of male spouses as the primary caregiver. In the Asian culture, women carry the traditional role as the informal carer for a sick family member. Female caregivers are more affected because caregiving affects their social functioning while male caregivers, particularly husbands of patients, are more distressed about work-related and financial issues. Our finding also supports that burden is significant between gender.

Caregiving is not a traditional role for a man. The difference between male and female caregivers is that male caregivers were more likely to perceive their role as beneficial. They gained satisfaction from the caregiving experience, and this increased their self-esteem. Regardless of whether the male caregivers are competent in providing care or getting additional help, it appeared that their involvement is positive and less stressful to them (Kim, Baker \& Spillers, 2007). The other possible explanation for the gender difference may be men's need to hide their frailty (Franchini et al., 2019). Men did not report their own distress, as it will show their weakness. Hence, a self- reported questionnaire might fail to capture their genuine emotions. It is suggested in the future to use validated tools to measure the psychosocial impact. On the other hand, positive adaptation was significant according to gender, where male caregivers reported lower score than females. Men had lower coping skills, but we did not explore.

We found that the relationship between the caregiver and the patient was significant across gender. Lim et al. (2016) reported that those who had parental relationships with their care recipient were found to have an impaired QOL. In addition, being the spouse and parent of the patient had a significant effect on the quality of life of the caregivers. Relationship between the caregiver and the patient decreases the QOL of the caregiver (Turkoglu \& Kilic, 2012). Parents who are caregivers were found to have impaired QOL because of the lack of social support during the caregiving process. This is because their other children may not yet be able to assist them with caregiving (Lim et al., 2016). Regarding gender role, female caregivers were more likely to perceive their cancer caregiving experience as stressful, particularly among adult caregivers. The adult daughters may have to perform multiple roles such as carrying out household tasks and personal care, which are burdensome and time-consuming (Kim, Baker \& Spillers, 2007). On the other hand, Doubova and Infante-Castaneda (2016) reported that the relationship factor was not significant.

Our study found that the education level is significant. Higher education contributed to a higher HRQOL (Duobova \& InfanteCastaneda, 2016; Zhu et al., 2013.) In addition, other factors were also significant such as employment status and household income. The employment and financial factors are interconnected. Having employment contributed to the lessening of the financial burden. Women who are employed have higher risk of losing their job due to having multiple tasks to perform, compared to men. But Li et al. (2016) found that employment was not a significant predictor. In regards to income, having a low income is associated with low HRQOL (Lim et al., 2016; Turkoglu \& Kilic 2012; Zhu et al., 2013). However, one study reported that those with high household (Son et al., 2012) 
were more likely to have more financial concern. High expectation for provision of healthcare may be the contributing factor for the concern.

Our study found that the presence of disease was significant across gender. This finding is incongruent to another study. The numbers of co-morbidities were not a significant contributor to cancer caregivers' HRQOL (Son et al., 2012) Caregivers put the needs of the patients ahead of them. Hence, they neglected their own needs. Our finding reported that additional factors that included sleep interruption are significant across gender that may impact the presence of disease. Besides that, they provided care without prior training and are expected to meet the demands with minimal support. Because of this, caregivers may experience greater distress and depression, which resulted in low QOL (Almutairi et al.,2017). This study has demonstrated that the caregivers; appraisal of their caregiving experience strongly influenced their QOL. This information adds to the existing cancer caregiving literature (Kim, Baker \& Spillers, 2007). This study can be implied to caregivers of other chronic conditions.

\subsection{Limitations}

This is a cross-sectional study that lacks a causal relationship. Although this study sampled patients at various stages of cancer (stages one to four), we did not explore the HRQOL throughout the whole trajectory of spousal caregiving experience from the time of diagnosis until the bereavement period. Their quality of life might fluctuate throughout the caregiving process. Further analysis was also not conducted in this study to determine the contribution of these factors towards the HRQOL scores of the caregivers. This study only recruited caregivers who attended the respective hospitals. Caregivers who did not receive hospital assistance in the caregiving process may experience worse QOL. There is a need to measure caregiving experience using multiple methods in the future for a more comprehensive picture.

\subsection{Conclusion \& Recommendations}

This study concluded that male caregivers reported significantly better HRQOL compared to their female counterparts. Factors that were significantly different between males and females were: the relationship between the caregiver and the patient; education level; employment status, marital status, household income and presence of disease. The findings of this study can be implied to caregivers of other chronic conditions.

Clinicians and healthcare support staffs have an essential role in supporting not only cancer patients but also their primary caregivers, due to the growing evidence that caregiving in cancer influence the family caregivers' quality of life, There is a need to provide appropriate support and services that are sensitive to role gender and targeted specifically at reducing the considerable strain of caring for cancer patients. This will also help cancer patients by increasing their long-term well-being, survival and QOL. Caregivers require support, coordination, and communication with health care providers if they are to be successful in carrying out their tasks of care.

Policymakers can provide a referral health system and better health support system such as psychological counselling, support group and financial support for the caregivers. As the caregiver is the key person in maintaining the patient in the community, both prevention and treatment of health problems among caregivers should be implemented. The ability of caregivers to provide good care can help to reduce the need for hospitalisation of patients or, at least, reduce the frequency of admission.

\section{Acknowledgement}

We want to express our gratitude to the health personnel who assisted with the data collection. We also thank the respondents who gave their full participation in the study.

\section{Paper Contribution to Related Field of Study}

This paper's findings contributed to the role of gender in caregiving practices of chronic diseases such as cancer. The health care providers must acknowledge that gender perceived caregiving differently. Hence, their needs for health care differ.

\section{References}

Almutairi, K. M., Alodhayani, A. A., Alonazi, W. B. \& Vinluan, J. M. (2017). Assessment of health-related quality of life among caregivers of patients with cancer diagnosis: a cross-sectional study in Saudi Arabia. Journal of Religion and Health, 56(1), 226-237.

Azizah, Ab. M.,Nor Saleha,I.T.,Nor Hashimah,A.,Mastulu,W.(2015).Malaysian National Cancer Registry Report 2007-2011.Putrajaya: National Cancer Institute.

Azizan, N. H., \& Mahmud, Z. (2018). Determinants of Subjective Well-Being: A Systematic Review. Environment-Behaviour Proceedings Journal, 3 (7), 135.

Chraif, M., \& Dumitru, D. (2015). Gender differences on well-being and quality of life at young students at psychology. Procedia-Social and Behavioral Sciences, 180, 1579-1583.

Duobova, S. V. \& Infante-Castaneda, C. (2016). Factors associated with Quality of Life of caregivers of Mexican cancer patients. Qual Life Res, 25,2931-2940. 
Franchini, L., Ercolani, G., Ostan, R., Raccichini, M., Samolsky-Dekel, A., Malerba, M. B., \& Pannuti, R. (2019). Caregivers in home palliative care: gender, psychological aspects, and patient's functional status as main predictors for their quality of life. Supportive Care in Cancer, 1-9.

Kim, Y., Baker, F., \& Spillers, R. L. (2007). Cancer caregivers' quality of life: effects of gender, relationship, and appraisal. Journal of pain and symptom management, 34(3), 294-304.

Li, Q.P., Mak,Y.W., Loke, A.Y. (2012). Spouses' experience of caregiving for cancer patients: a literature review. International Nursing Review,178-187

Lim, H.A., Tan, J.Y.S., Chua, J., Yoong, R. K.L.,Lim, S. E., Kua, E. H., \& Mahendran, R.(2016). Quality of life of family caregivers of cancer patients in Singapore and globally. Singapore Medical Journal, 1,1-13.

Lua, P. L., Norhayati, M., \& Ahmad Kashfi, A. R. (2013). HRQoL profile and psychometric properties assessment of caregiver quality of life instrument among HIV/AIDS family caregivers in Terengganu. Malaysian Journal of Psychiatry, 1,1-4

Mohit, M. A. (2018). Quality-of-Life Studies in Natural and Built Environment: Challenges and emerging issues. Asian Journal of Behavioural Studies (AjBeS), 3(10), 147157.

Son, K.Y., Lee, C.H., Park, S.M., Lee, C.H., Oh, S.I., Oh, B., Tak, S.H., Cho, B., Lee, K. \& Lee, S.H. (2012). The factors associated with the quality of life of the spouse caregivers of patients with cancer: a cross-sectional study. Journal of Palliative Medicine, 15(2), $216-224$

Turkoglu, N., \& Kilic, D. (2012). Effects of care burdens of caregivers of cancer patients on their quality of life. Asian Pacific Journal of Cancer Prevention, 13(8), 41414145 .

Weitzner, M.A., Jacobsen, P.B., Wagner Jr,H., Friedland, J., \& Cox, C. (1999). The Caregiver Quality of Life Index-Cancer (CQOLC) scale: development and validation of an instrument to measure quality of life of the family caregiver of patients with cancer. Quality of Life Research Int J Qual Life Asp Treat Care Rehab, 8(1-2), 55-63.

Zhu, P., Fu, J-F., Wang, B., Lin, J., Wang, Y., Fang, N-N., \& Wang, D-D. (2013). Quality of life of male spouse caregivers for breast cancer patients in China. Asian Pacific Journal of Cancer Prevention, 15(10), 4181-4185. 